\section{The Human Genome Project—Pharmacogenomics: How Will It Affect the Role of Pharmacists?}

Dear Editor:

The Human Genome Project (HGP) is expected to have a major impact on the field of medicine and revolutionize the delivery of drugs. ${ }^{1,2}$ With the power to identify the error in the gene and correct the same, the focus of medicine may shift from treatment to prevention. The impact of the HGP could also affect the pharmacist and the practice of pharmacy.1-3 The advent of the HGP may lead to the development of drugs tailor-made to each patient's genetic profile. The applications of the HGP to pharmacy and pharmacy practice are numerous. It is imperative that pharmacists keep up with the ever-increasing pool of knowledge regarding the HGP and pharmacogenomics. ${ }^{2}$

In the July/August 2002 issue of this Journal, Zachry and Armstrong presented data regarding health care professionals' perceptions of the role of pharmacogenomic data. ${ }^{4}$ They concluded that participants in their study were optimistic about the benefits and uses of pharmacogenomic data. The study participants were those who had recently attended a conference titled "Pharmacogenomics: Implications for Patients, Providers and Payers." Clearly this information may have affected the views of the respondents, as discussed by the authors. ${ }^{4}$ However, there are many questions about the HPG. Are practicing pharmacists aware of the advances in the HGP, and do they have knowledge of pharmacogenomics? Do they have information about the impact of the HGP on pharmacy practice? Do pharmacists have the knowledge necessary to counsel patients on the correct use of the drugs? These and several other questions that involve the pharmacist role with the advent of the HGP and the increasing knowledge in pharmacogenomics need to be addressed.

The answers to some of these questions were the bases of a study we conducted to evaluate the impact of the HGP on the professional role of community pharmacists. ${ }^{5}$ Preliminary results of our study mimic those reported in the article by Zachry and Armstrong. ${ }^{4}$ In our study, we also ascertained the knowledge pharmacists presumed they possessed regarding the HGP and pharmacogenomics. ${ }^{5}$ In this study of 376 pharmacists working in a community setting, we found that the pharmacists' confidence in their knowledge regarding HGP and pharmacogenomics was around $40 \%$ on a scale from 0 to $100 . .^{5}$

Pharmacists in our study indicated that all patients should have access to their genetic profile $(3.78 \pm 1.05$, range $1-5) .{ }^{5}$ In addition, they agreed that health care providers should have access to patients' genetic information to help patients improve their health $(3.40 \pm 1.11)$. They disagreed that health insurance plans should have access to patients' genetic information $(1.98 \pm 0.99)$ and agreed that health plans would discriminate against potential customers if they had access to such information $(3.92 \pm 0.98)$. They also disagreed that such data should be available to employers $(1.68 \pm 0.97)$.

Continuing education credits in the field of pharmacogenomics should keep pharmacists abreast of the current advances of the HGP and their implications. Conferences such as those described in the article by Zachry and Armstrong should be encouraged. ${ }^{4}$ Pharmacists in our study agreed that they should be required to take at least $2 \mathrm{CE}$ credits on human genetics $(3.53 \pm 0.96) . .^{5}$ The community pharmacists were also of the opinion that colleges of pharmacy should include topics on the advances of the HGP in their curriculum $(3.71 \pm 0.88)$ and that this information would prove highly advantageous to future pharmacists. The pharmacists believed that this information would not only help them learn about the HGP but also help them tremendously in patient counseling $(3.71 \pm 0.85) .^{5}$

New developments in the HGP necessitate training pharmacists in handling drugs developed as a result of advances in the HGP. The community pharmacists we surveyed believed firmly in this fact $(3.92 \pm 0.71)$, further agreeing that the role of the pharmacist will change in the future due to advances in the HGP $(3.41 \pm 0.96) .{ }^{5}$ The mapping of the human genome is a monumental discovery in the field of medicine, but in the absence of adequately disseminated knowledge regarding this project, the magnitude of the HGP will not be fully realized.

Amit S. Kulkarni, MS candidate
Department of Clinical Sciences and Administration, College of Pharmacy,
University of Houston, Texas Medical Center

Sujit S. Sansgiry, PhD, Assistant Professor Department of Clinical Sciences and Administration, College of Pharmacy, University of Houston, Texas Medical Center

\section{REFERENCES}

1. Carrico JM. Human Genome Project and pharmacogenomics-implications for pharmacy. J Am Pharm Assoc. 2000;40:115-16.

2. Jaggers LD. Pharmacogenomics: worthy of pharmacy's attention. Am J HealthSyst Pharm. 1999;56:27.

3. Scott BE. Focus on the future: ASHP 2000. Am J Health-Syst Pharm. 2000;57:465-66

4. Zachry III WM, Armstrong EP. Health care professionals' perceptions of the role of pharmacogenomic data. J Managed Care Pharm. 2002; 8(4):278-84

5. Kulkarni A, Shringarpure G, Ghafoor A, Sansgiry SS. Community pharmacists' knowledge regarding the Human Genome Project. Paper (poster) presented at: 2002 AACP Annual Meeting; July 2002; Kansas City, Missouri.

\section{Pharmatopia}

Dear Editor:

All stakeholders within the pharmaceutical supply, distribution, and consumption chain have their own agenda. The stakeholders-patients, health professionals, plan sponsors, pharmaceutical companies, and governments - may learn from each other's point of view. What would Pharmatopia, the fictional land where the drug system favors the inhabitants, look like from the perspective of each constituent?

Pharmaceutical manufacturers in Pharmatopia see all research results in salable compounds. The FDA approves all compounds. Patents do not expire. Physicians write prescriptions for brandname drugs only. No restrictions are placed on advertising to consumers or physicians. There are no formularies. Plan sponsors do 
not restrict access to any drug or class.

The FDA in Pharmatopia finds that all drugs are safe, effective, and can be used over-the-counter. Manufacturers make no unsubstantiated claims. Congress does not second-guess FDA rulings.

From the prescribers' view of Pharmatopia, all drugs work. No drug has a side effect or harmful interaction. Any drug on the market is appropriate for all patients and may be used without restriction. Patients do not ask for specific drugs when they visit. Pharmacists need not call for prior authorizations or formulary alternatives.

For patients in Pharmatopia, all drugs are accessible without restriction or copayment. All drugs work and have no side effects or harmful interactions. Their employers have plenty of money after paying for health care and offer large, annual raises.

For pharmacists in Pharmatopia, physicians write legibly or submit all prescriptions electronically. There are no drug shortages or recalls. All drugs are available generically. There is no shortage of pharmacists. Dispensing fees are adequate, and prescription volume allows time for extensive patient counseling.

Pharmatopia for plan sponsors (state, federal, and private employers) is quite intricately woven. The FDA is shut down so that no new blockbuster drugs make it to market. All members from the $\mathrm{CEO}$ /governor/president on down are on a single drugbenefit plan. Members take only the medications that they need to maintain their health and insist on having premiums and copayments. Members with chronic problems take the medications needed to maintain health and avoid deterioration.

Pharmacy Benefit Managers (PBMs) and other providers of pharmaceutical care have an ambitious view of Pharmatopia. All citizens work and have a pharmacy benefit. Pharmaceutical spend trend can be managed to the negative side. Members understand their pharmaceutical benefit and use it appropriately. All plan sponsors appropriately implement every clinical program. All claims adjudicate, resulting in no call volume. Pharmacists are satisfied with their reimbursement. Pharmaceutical manufactures offer large discounts without regard to volume.

The Congressional view of Pharmatopia includes the availability of all drugs from Canada. The elderly use fewer drugs as they age and use their savings to purchase the drugs that they consume. Pharmatopia can be legislated. Everyone votes for the incumbent.

\section{A Dose of Reality}

The chemical and pharmacological properties of drugs are examples of natural trade-offs: effects versus side effects. Within the delivery system, one constituency's Pharmatopia is another's bane. The system cannot simultaneously have only brand-name drugs and only generics. New chemical entities are expensive to bring to market and must support those that never become approved. The FDA exists to protect citizens from ineffective or toxic substances and unsubstantiated claims. Drug interactions play a major role in prescribing decisions.

Drug spend trend continues in double digits even with aggressive management. Formularies continue to be used as a tool to steer drug use to the safest, most cost-effective therapy and promote rational therapeutics. Generic drugs lower the cost of drugs to patients, health plans, and governments. Patients ask for drugs that they see advertised whether or not they are appropriate. Sponsors are unwilling to spend money on lifestyle drugs in order to conserve resources for life-saving therapies.

\section{Universal Pharmatopia}

If stakeholders receive some of the items from their personal Pharmatopia and the system runs most efficiently, then Universal Pharmatopia might take the following shape.

Drug companies keep doing research and enjoy, but don't abuse, the normal patent life. The FDA assures that safe and effective medications reach the market in a timely manner and does not compromise effective prescription drugs into ineffective OTCs by halving dosages. Prescribers take the time to briefly explain why an older drug really is best when patients ask for a particular brand. Practitioners write prescriptions for generics whenever they have the opportunity and embrace the technology that replaces the prescription pad. Patients follow their physicians' advice and use generics or over-the-counter drugs when available. People get used to paying a larger portion of their own medication expenses instead of looking for someone else to pay for what they consume. Patients resist incessant direct-to-consumer advertising of new drugs. Pharmacists negotiate a fair reimbursement contract-and then perform. Technology is adopted to streamline the entire drug delivery system, especially at the point of service. Plan sponsors promote or mandate generics and use quantity limits and prior authorization judiciously. Other clinical programs are tried; success is rewarded. PBMs and other providers of pharmaceutical care continue to offer value in management of drugs to enhance the well-being of members. The plans prosper and the providers share in the success. The U.S. Congress does not buy into the reimportation scam for shortterm benefit but reduces direct-to-consumer advertising. If a Medicare prescription drug benefit is enacted, it is means-based and does not produce undue burdens on future generations.

Drugs provide huge health and societal benefits when used properly. The pharmaceutical supply chain must remain profitable for the producers and affordable for consumers. While each constituency brings its own needs and biases, the goal is to wring the waste out of the system while assuring progress against the real villains-disease and suffering.

A system of checks and balances in which everyone wins something may be all that can be expected, but innovations may still add to efficiencies and bring us all closer to Pharmatopia.

Steven M. Pepin, PharmD, BCPS Principal PHARMWORKS, LLC

"Forging Drug Thought" spepin@PHARMWORKS.com 